\title{
Research on Security Assessment of Highway Slope Protection by using NURBS modeling: an Ecological Perspective
}

\author{
Hongxiu Liu ${ }^{1, *}$ and Bohang Sun ${ }^{2}$ \\ ${ }^{1}$ North China University of Science and Technology, Tangshan 063000, China \\ ${ }^{2}$ Tangshan College, Tangshan, China \\ *lhxt2008@126.com
}

\begin{abstract}
Virtual reality means that people use the computer to visualize complex data and realtime interaction. In this paper, the authors proposed a $3 D$ geological modeling for slope engineering by using Non-Uniform Rational B-Splines (NURBS) surface function. By analyzing the commonly used $3 D$ data structure, we construct a $3 D$ solid modeling of complex slope, which combined with the advantages of NURBS surface and B-Rep entity. The results show that the realization of $3 D$ geological visualization can be used as the decision basis for the slope engineering construction. At the same time, the author analyzed the greening slope that could prevent water and soil loss, and put forward the importance of slope greening protection from the view of ecological protection.
\end{abstract}

Keywords: Non-Uniform Rational B-Splines, slope protection, security assessment, X3D technology

\section{Introduction}

In recent years, in order to adapt to the rapid development of society and economy, the rapid development of the highway, at the same time, the contradiction between highway construction and environmental protection has become increasingly prominent. On the one hand, in order to keep the economy stable and sustainable development of society and rapid progress, our investment in infrastructure, especially highway investment will continue to increase[1]. On the other hand, with the infrastructure it is bound to large excavation new slope and tunnel, this will of the original vegetation and ecological environment caused destruction of a new round of, on Soil and water conservation, ecological protection, environmental pollution produced extremely unfavorable influence, caused huge losses. Ecological protection technology is a kind of engineering technology with the construction of Expressway in the world and the rise, different from the traditional engineering protection technology; ecological protection technology makes full use of the plant's own characteristics, combined with the necessary engineering protection to the engineering construction and the environmental protection both[2]. In today to pay more and more attention to the environmental protection and quality of life, ecological protection has become a trend of highway slope protection, it represents the development direction of slope protection, and finalizes the design model of expressway slope eco engineering in our country currently no successful experience, no more technical specifications to follow[3]. Currently research of eco protection technology mainly concentrated while maintaining a research on construction process and soil, neglect slope of plant root system of engineering mechanics behavior of research combined with plant protection and engineering protection door, leading to the door theory lags far behind the development of protection technology application, to restrict the application of ecological protection technology in slope Engineering.

The West and Japan and other developed countries slope protection measures after long-term of highway slope construction and reinforcement of practice and research, by 
the door of project development in the past into now with protective engineering and biological protective door system. It is to use living plants, separate plants or plant and civil engineering and non-life of plant material combination, to reduce the slope stability and erosion; most of the countries in the world attach great importance to the greening of expressway slope, countries have been in-depth and meticulous research[4-5]. It has developed from the past to the current common green protection to the present ecological, environmental protection, human, landscape greening protection. Countries such as the United States and Japan in this research is the most representative, they in the highway design, generally do not advocate the line high filling and excavation, try to slow slope slope rate, because it is in the interests of the slope protection and greening. The United States and other countries as early as twentieth Century three, forty years to realize the necessity and importance of the protection of the ecological balance of the necessary and importance, it began to carry out the technical research of vegetation restoration work and the application of the highway slope[6]. Green project" subject terms by Kurada Masujiro in the 50's of the last century, Japan first proposed. For decades Japan in highway construction in the practice gradually invented as a variety of disaster prevention green, laccolith greening, bag reinforced greening and spray attached green this in view of the different types of slope greening technology[7]. In the eighties of the 20th century, the external soil spray sowing technology in wet spray sowing technology based on has been developed, completely solve the planting of this problem on the rocky slope, which is greening and protection technology of a big progress.

Due to the impact of China's national conditions in the early stage of China's highway construction, the greening of the research work is mainly in the slope of biological protection on the one hand. The main method is the use of exotic herbs, so that the highway side slope is destroyed in the construction of the place and the slope of the rapid greening protection. Along with our country highway slope biological protection continuously in-depth study, early slope biological protection mainly use planting, artificial seeding, sodding etc., the technical efficiency is low, effect is poor, backward, the vegetation is not up to the fast recovery. Since the early 90s of the 20th century, we gradually discovered exotic herbaceous species cannot meet the local highway slope greening protection requirements, mainly for acclimatization ability is poor, door time is short, door of the effect is not obvious, cutting slope and nature cannot be perfect with financial integration, began to use the native plant species were green research, and from the single herb to try using a variety of shrubs and trees and lianas, and to domestic introduced the concept of slope eco engineering.

\section{High Slope 3D Geological Modeling}

\subsection{NURBS Structure}

Slope engineering 3D modeling based data organization and expression is the basis of 3D modeling of engineering slope, ground structure of rock high slope engineering modeling study area, underground structures and geological structure is very complex, modeling data information and $3 \mathrm{D}$ visualization analysis requirements. Therefore, it is the key to build the 3D model of complex slope engineering to select and establish the appropriate 3D data structure. By analyzing the commonly used 3D data structure, combined with the advantages of reducing the 3D data structure of the NURBS surface and the B-Rep entity, a 3D data structure for 3D solid modeling of complex slope engineering is established.

Assuming a $(\mathrm{M}+1)^{*}(\mathrm{n}+1)$ block shaped NURBS surface, its grid control point $\mathrm{d}$ is $\left(\mathrm{x}_{\mathrm{i}, \mathrm{j}}, \mathrm{y}_{\mathrm{i}, \mathrm{j}}, \mathrm{z}_{\mathrm{i}, \mathrm{j}}\right), 0 \leq i \leq m, \quad 0 \leq j \leq n$, the surface can be defined by the following formula. 


$$
\begin{gathered}
s(u, v)=\frac{x(u, v)}{w(u, v)}=\frac{\sum_{i=0}^{m} \sum_{j=0}^{n} w_{i}, \vec{d}_{i}, N_{i}^{p}(u) N_{j}^{q}(v)}{\sum_{i=0}^{m} \sum_{j=0}^{n} w_{i}, N_{i}^{p}(u) N_{j}^{q}(v)} \\
\left(u \in\left[u_{p-1}, u_{m+1}\right], v \in\left[u_{q-1}, u_{n+1}\right]\right)
\end{gathered}
$$

In practical engineering, known control points and boundary line of surface ground and geological structure control information can be as surface fitting the actual data set, namely, the need to according to the given NURBS surface data point set, initial parameters and node distribution, back calculation parameter function surfaces $s$ and a weight $\mathrm{W}$, and find the known data sets of NURBS surface function.

\subsection{Slope NURBS Modeling}

Slope excavation surface is the main form of ground excavation structure, slope excavation geometry morphology basis of slope excavation and support design data provided structure excavation line and control points, slope excavation control lines into a set of boundary of NURBS surface to describe. Slope engineering of underground foundation processing structure is usually composed of several underground cavern collections, according to the underground cavern design diagram for each underground cavern object chamber section and the center line, using the NURBS surface scanning path space curved surface function parameters to describe. Slope engineering geologic structure complexity, diversity and uncertainty; because the geological information obtained by geological drilling and tunnel is very limited, the correct analysis of slope engineering geologic structure of space form is key to ensure the slope engineering of 3D geological model correctness and precision. Through the analysis of the slope engineering geologic structure, can clearly understand slope engineering complex regional geological structure of geometric shape and spatial relations, the main object of analysis of geological structure, including lithology, geological structure, according to the geological profile can be obtained by analyzing provided geological structure interface control and reduction of the boundary information, determine the geological structure of the interface of trimmed NURBS surface function.
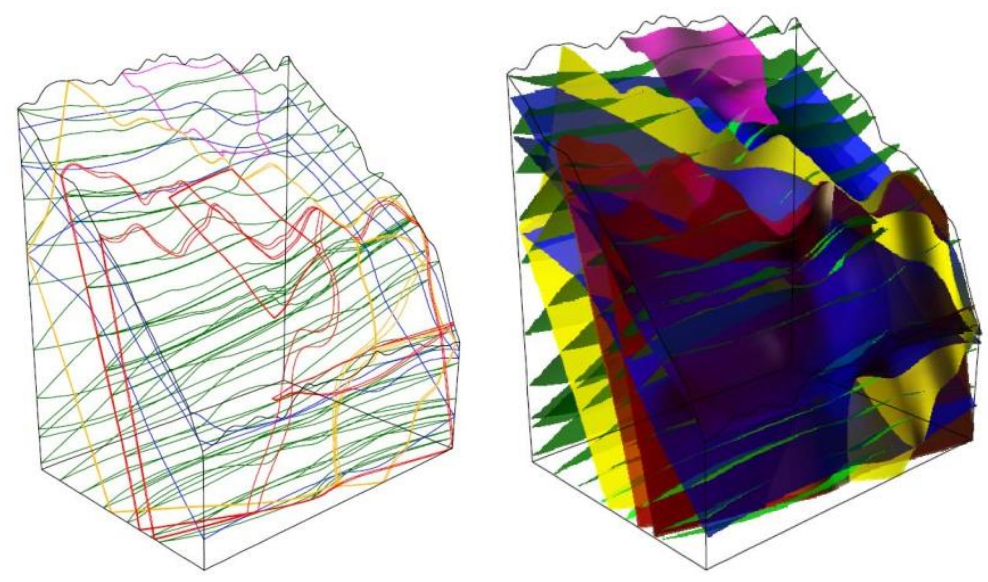

Figure 1. Trimmed-NURBS Modeling of Geological Structure Interfaces 


\section{Disaster Prevention Slope}

\subsection{Engineering Examples of Slope Diseases}

Highway roadcut slope along, due to the complex topography, serious weathering degree of rock mass, rock breakage is serious, joints, fissures, cracks between infiltration larger amount of water and other reasons, caused the slope disasters occur frequently[8]. Taking the engineering example of high-speed collapse, landslide, slump and collapse of four kinds of slope diseases are introduced as follows:

1) Avalanche: the slope is in the low mountain engineering geological area, the terrain is steep, for the conglomerate rock high slope, by silty clay, strong weathering conglomerate, medium weathered conglomerate, and weathered mudstone sandstone and so on. After excavation, the slope formed an airport surface, under the effect of weight and external force caused by slope sliding along the vertical joint planes, with gravel accumulation in the toe.

2) Landslide: the slope is in the low mountain engineering geological area, for the earth rock structure high slope, belongs to a section of large ancient landslide body. The vertical joints and fissures are developed, which consist of silty soil, loess, strong weathered sandstone, mudstone, medium weathered sandstone and mudstone. The slope is temporarily in stable condition after excavation, but because of continuous rainfall, coupled with the slope front edge of the slope has been excavated, so there has been a landslide phenomenon.

3) Scattered: Slope is an ancient landslide area, the peak and the slope of the development of residual soil, gravel soil and silty clay. The slope after excavation is gravel soil, and the water content is large. Excavation of slope groundwater and rainfall weakened the strength of the lower part of the cushion; gravity causes the lower cushion layer compression extrusion, the pressure of the upper conglomerate along the steep crack effect lead to wrong on the surface of the slump.

4) Collapsing: The slope is in the marginal zone of the Loess beam region. The depth of the bedrock is deeper, the soil slope is basically the soil slope, and the slope is composed of loess, clay, strong weathered sandstone, medium weathered sandstone and so on. Slope excavation slope in the process of large cracks appeared, after rainfall reduces the strength of rock mass, weight increases, the slope under the action of gravity, along the surface fixed collapse to granular shaped pile on the foot of the slope.
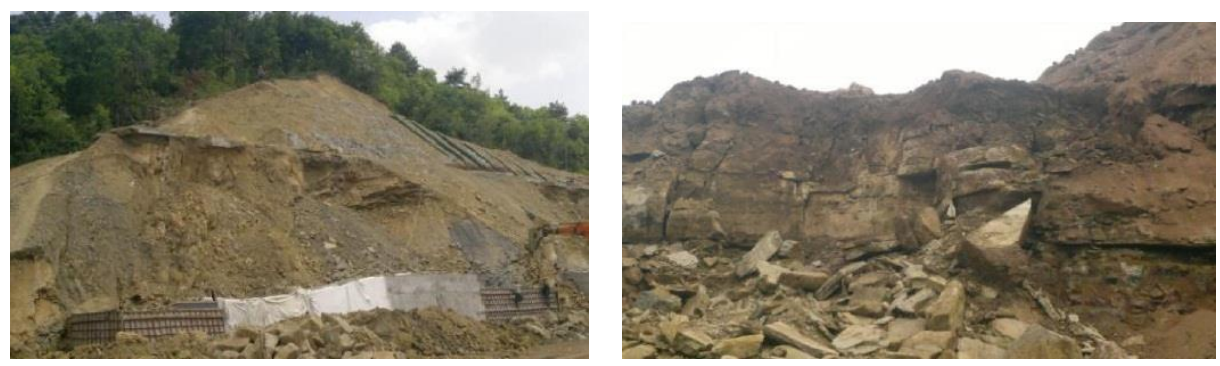

Figure 2. Slope Collapse and Landslide 

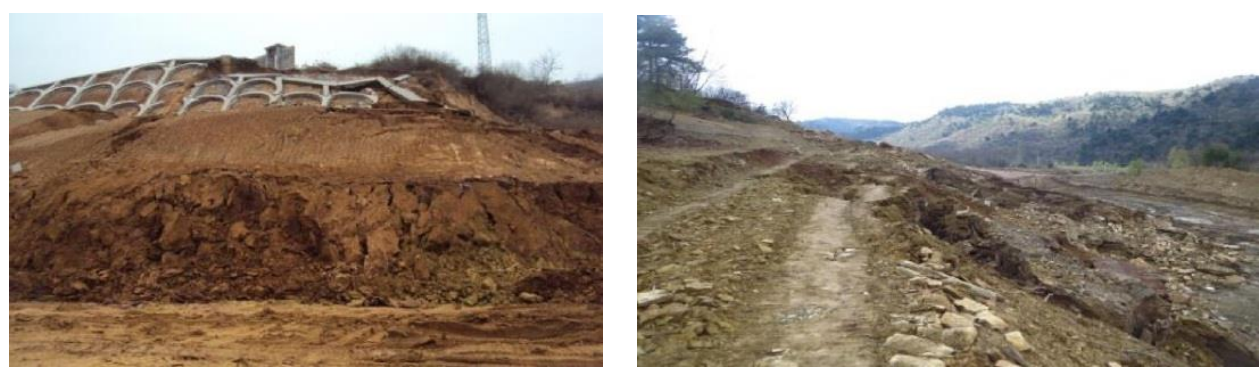

Figure 3. Slope Scattered and Collapse

\subsection{Soil Erosion Type Slope}

This kind of slope destroyed the original natural vegetation cover layer in the process of production, resulting in the loss of stability of the shallow slope, and easy to produce surface soil and water loss. Soil erosion slope occurred in the soil slope or weathered rock slope, excavation slope and high impact larger rock in gravity, hydro, wind and other external should force, slope erosion and destruction, soil and water loss phenomenon. In addition, in the larger rainfall area, this type of slope is also the focus of protection. Slope biological protection is to prevent water and soil erosion, maintain ecological balance; two is to beautify the environment, the stability of the roadbed. Excavation section of soil slope, to do everything possible to make the slowing down the slope and the shrubs planted on the crest of a hill, slope with turf revetment again appropriate embellishment perennial flowers or plots planted shrubs of measures and so on; the rocky side slope excavation section does not have the conditions for the survival of plants, can use to pull the geogrid in the rock after laying solid soil materials for ridge planting grass, in the rock slope will be climbing plants or overhanging plants in the chisel groove ridge planting, to plant trees and shrubs in the upper slope platform measures. Can be in the fill section of conical slope and re toe of slope and slope planted, climbing or hanging plants, such as pashanhu plants; fill the soil slope can be grass, vines, and shrubs and other organic coordination, the combination of a variety of plant configurations. Shrub and vine garden for the slope, it is soil and water conservation ability, adapt to a wide range of security; although the landscape beautification effect is inferior to that of arbor, shrub and grass green way, but fortunately all slope greening protection can be large-scale, wide range of application.
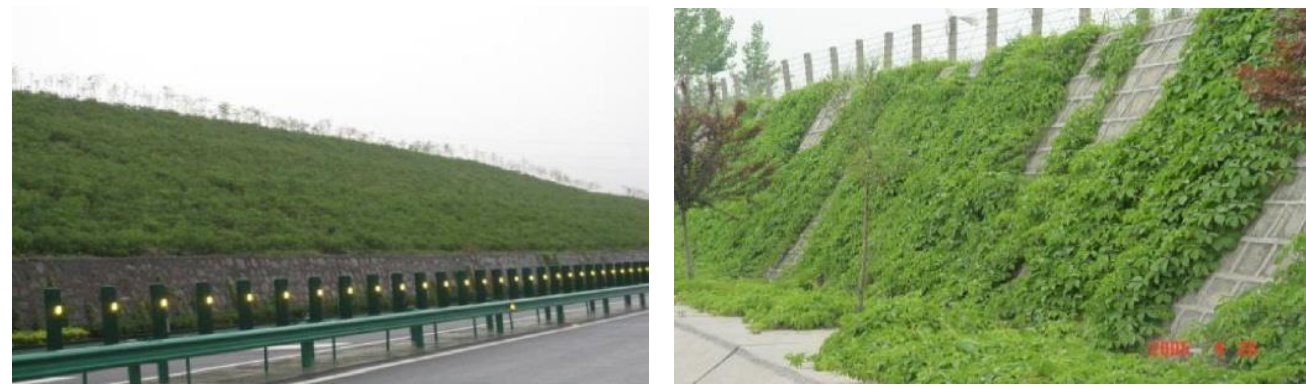

Figure 4. Lawn Type Slope Protection

Slope protection engineering types, there are many methods, such as concrete skeleton slope protection, precast concrete slope protection, concrete slope protection, active flexible door, passive flexible door, anchored slope protection. No matter what kind of protection type its ultimate goal is to achieve the reduction of soil erosion, slope stability, prevention of disasters and other effects. For high steep section of excavation slope and weathered rock slope, take the cast-in-situ concrete frame, and the intersection point installed fixed pile and anchor bar, anchor cable sash frame. This protection method is 
chosen because of its good mechanical properties, economy, application, and environment and so on.
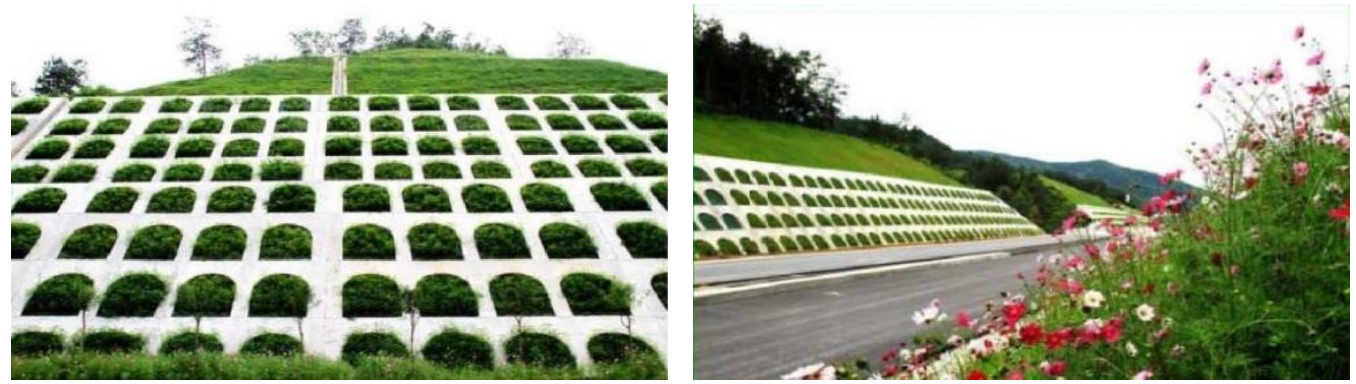

Figure 5. Skeleton Slope Protection

\section{3D Geological Virtual Reality of Slope}

\subsection{Virtual Reality Technology and X3D Specification}

Virtual reality is the environment for people to visualize, operate and interact with complex data through computer. Virtual reality is the summary of 3 basic technologies: 3D computer graphics technology; interactive interface technology with multiple functional sensors; high resolution display technology. Virtual reality is, first of all, a visual interface technology, can effectively to build up a virtual environment, which is mainly concentrated in two aspects: one is the virtual environment can accurately represent the status of the object model; the second is environmental visualization and rendering. Virtual Reality Modeling Language (VRML) is technology of threedimensional network of the earliest international standards, it is a 3D modeling and interactive environment of simple text language description, with platform independent, based on Web, rapid modeling, and other advantages. Scalable 3D standard VRML is an upgrade of $\mathrm{X} 3 \mathrm{D}$, which has become an open network three-dimensional technical specification.

X3D provides support to the original VRML and browser, and the increase in the number of non VRML standard characteristics (such as NURBS surface), X3D to prototype (proto), node and route (route) in the form of description based on temporal behavior, interactive 3D and multimedia information abstraction function to achieve in Multimedia Integration Based on network communication interactive 3D content, can be used for scientific visualization, aerospace simulation, virtual battlefield. X3D scene file is a kind of explanation implementation, real-time modeling and coloring the text in the program, it through the application is defined by the various proto Standard Code constitutes a scene graph to describe the 3D scene, support VRML2.0 and XML encoding method, the structure of the XML encoding of X3D file as shown. In view of the X3D flexible scene interaction and the support of the NURBS geometry model, the 3D geological model of the slope engineering three-dimensional geological model can be used in real-time dynamic visualization display and three-dimensional visualization query by X3D. 


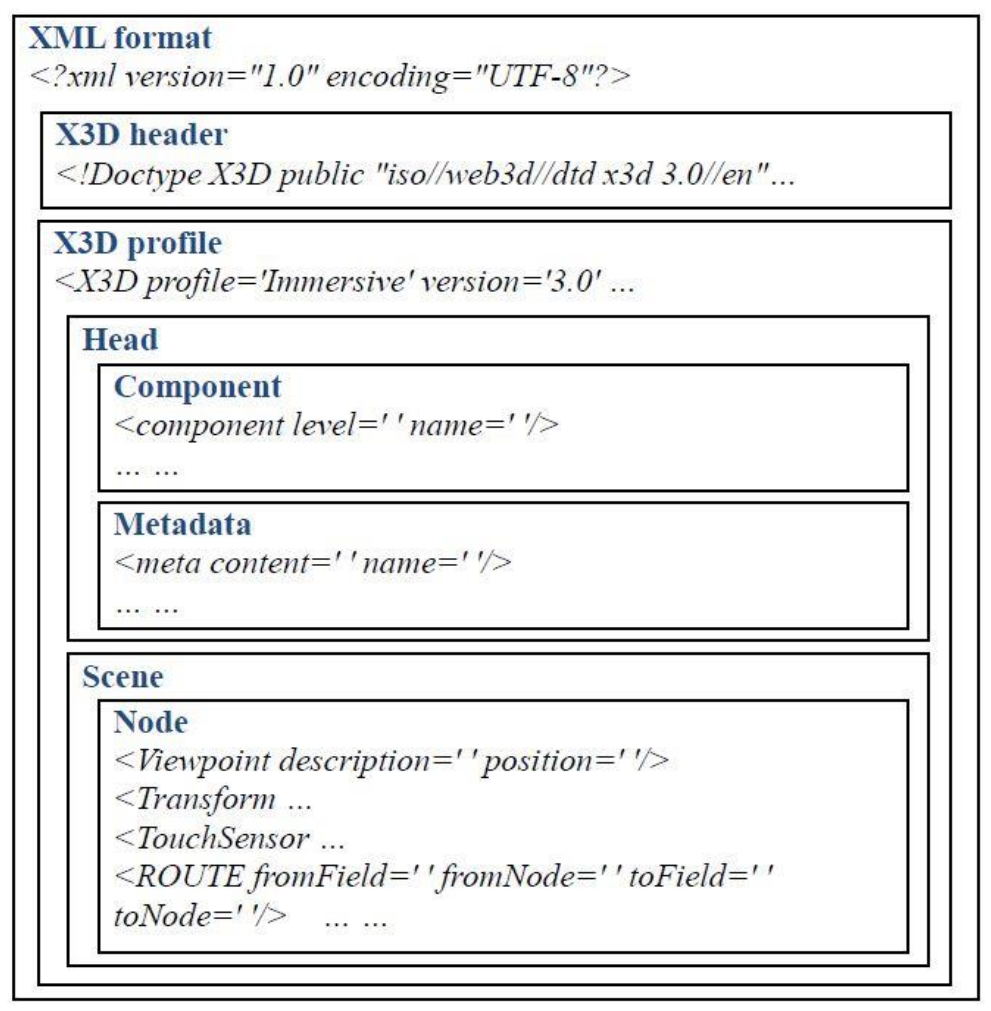

Figure 6. X3D File Structure

\subsection{D Geological Visualization of Slope}

4.2.1. The X3D Prototype of NURBS Surface: The X3D specification contains a variety of geometric shapes and forms, including basic geometric body (box, cone, cylinder, sphere), grid (grid), patch IndexedFaceSet 3D modeling. X3D scalability is achieved through a custom prototype, through the definition of NURBS curves and surfaces of the prototype can be achieved NURBS support for X3D. The X3D specification complete set contains the definition of NURBS prototype, mainly including: 1.Contour2D sub node node, node is used to assemble a group of curves, to form a closed curve; 2 NurbsCurve2D/NurbsCurve nodes, NURBS 2D / 3D curve in X3D scenes show that this node contains a subset of nodes is used to define the control point 3.NurbsPatchSurface; node, expression of 3D NURBS block shape surface in the X3D scene, which contains 2 sub nodes, are used to define the control points and texture coordinates; 4 NurbsSweptSurface/NurbsSwungSurface nodes, a sweeping surface formed by including a profile curve and a curve path node; 5.NurbsTrimmedSurface node, NurbsPatchSurface node said surface after cutting the 2D curve in Contour2D nodes, the nodes in need Contains a child node that represents the control point and a sub node that represents the texture coordinates. Surface trimming cut line can be many, therefore the node can contain multiple Contour2D as a child node, and can be in the scene are added or deleted; 6. NurbsSet node, which belongs to the group of nodes, for NURBS curve or surface set into a group, in order to facilitate the $\mathrm{X} 3 \mathrm{D}$ browser management and display these geometries, also can guarantee contains surface at the intersection of the crack. The above nodes are given the commonly used X3D structure of the NURBS expression, for a $5 \times 5$ X3D control parameters of the reduction of NURBS surface, can be defined in the following sections of the code: 


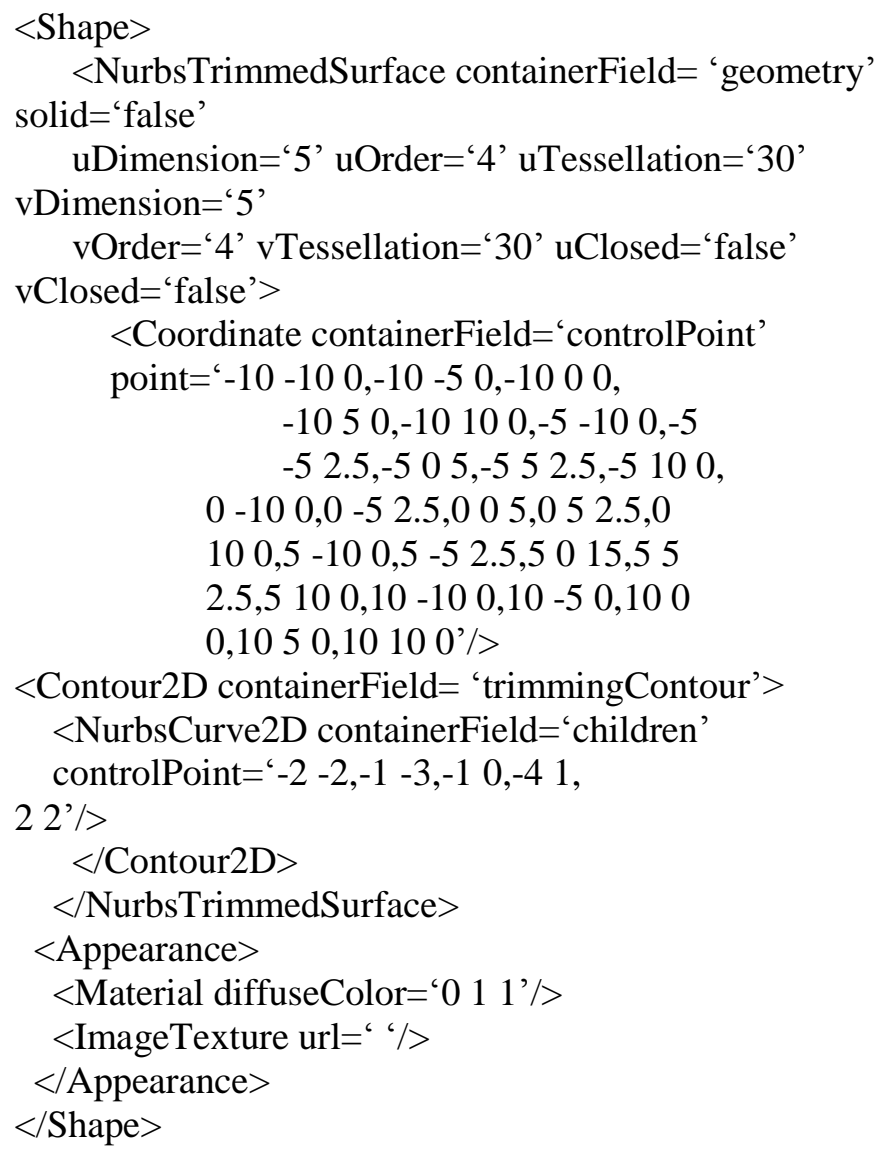

By above knowable, through the conversion will constitute a three-dimensional model of the slope engineering B-rep solid set of trimmed NURBS surface geometry information for X3D NURBS prototype defined curve and surface node form, to complete the threedimensional model of the slope engineering of X3D scene expression.

\subsubsection{Method for Constructing Virtual Reality Dynamic Scene of Slope Engineering:} Although X3D can organize all objects in the form of a scene graph by including relationships, it can be used to create a 3D scene with a hierarchical file format. But when the scene is very complex, is a very large number of scene geometry object, but also involves the complex relationship between the geometric object positions, so simple to use artificial way to write the $\mathrm{X} 3 \mathrm{D}$ scene code is clearly inappropriate, even using $\mathrm{X} 3 \mathrm{D}$ scene editor (such as X3D editor and VrmlPad, HomeSpace builder, VR Creator etc.) also difficult to deal with complex virtual reality scene construction. Slope engineering is a complex, dynamic system, the 3D model along with the progress of the construction project and will continue to change, such as ground, underground excavation, the need for dynamic scene 3D visualization of slope engineering is established, to project performance in different periods of image features, which is convenient for reasonable and intuitive visualization of 3D geological slope analysis. X3D rich API interface functions to make the dynamic generation and maintenance of the virtual reality scene possible. The 3D geological model of the slope engineering is stored by the database, and the dynamic construction of the X3D scene can be carried out in the process of the communication between the advanced programming language, the database and the X3D browser. SAI is a collection of API functions used to manipulate the X3D scene, X3D allows users to call the SAI interface functions to manipulate objects in the scene through the advanced programming language. You can use the SAI function in the Script node in the $\mathrm{X} 3 \mathrm{D}$ file, in the $\mathrm{X} 3 \mathrm{D}$ browser support conditions, can also be used in other applications in the X3D browser SAI browser. The main functions of SAI in the form of 
API function include: add or delete the virtual reality scene node; generate and receive events; establish and delete the routing relation; change or read the node belongs to operation or control of the X3D browser, including the view settings, UI mode switch.

\subsection{Engineering Application}

According to the above theory of three-dimensional geological modeling and visualization based on virtual reality technology route and application of BS contact X3D browser ActiveX components, in VisualBasic.Net programming environment developed the slope engineering geological 3D virtual reality visualization program. Query the 3D visualization of slope engineering as an example, respectively from the slope excavation image of 3D geological visualization simulation, geological conditions, safety monitoring section geological section cutting analysis, safety monitoring system for visual query and monitoring data comprehensive analysis slope 3D geological visualization in virtual reality applications. According to the B-Rep solid structure of the 3D geological model of the slope, the solid structure is further divided according to the elevation plane, the new B-Rep geometry is obtained and the corresponding time attribute is given. By changing the time variable CurTime of the virtual reality scene, the virtual reality visualization results of the image features of the slope project in different time periods can be obtained. Figure 7 the results of virtual reality visualization for high side slope. The realization of dynamic display of 3D geological visualization in the construction process of the excavated slope can be used as the decision basis for the advance prediction of the slope engineering construction geology.

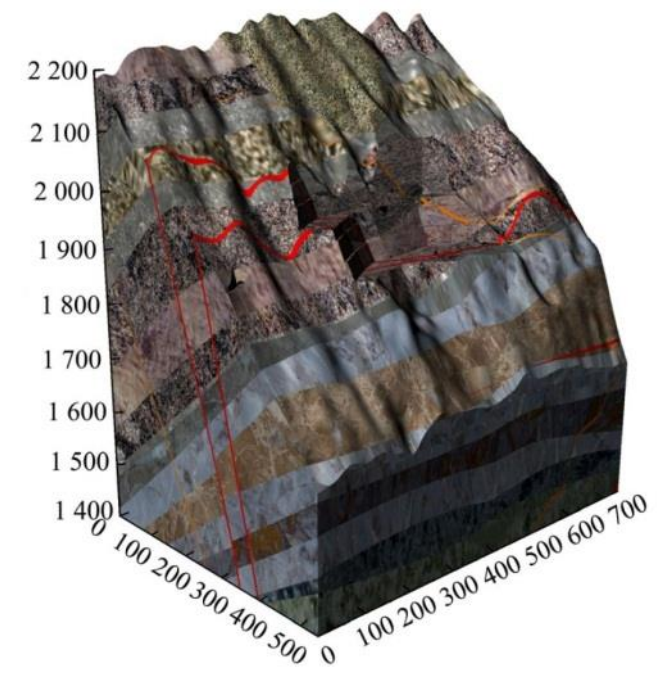

Figure 7. 3D Geological Visualization Analysis of Slope Excavation

By using the method of constructing the virtual reality dynamic scene, the 3D visualization of the 3D geological visualization of the side slope project based on the visual query parameters is realized. The main geological structure, weathering and unloading classification of the slope engineering modeling area are shown in Figure 8. Slope safety monitoring and analysis of common visualization degree is low, the lack of integration and real-time is insufficient, cannot intuitionistic analysis of monitoring data and geological conditions such as environmental information fusion, can not directly reflect the slope engineering of the whole working state. By means of B-rep entity structure flexible cutting characteristics, geological conditions of safety monitoring section of virtual reality visualization analysis of intuitive, for safety monitoring and measuring point and line monitoring physical variation and where the regional geological characteristics of association analysis. 


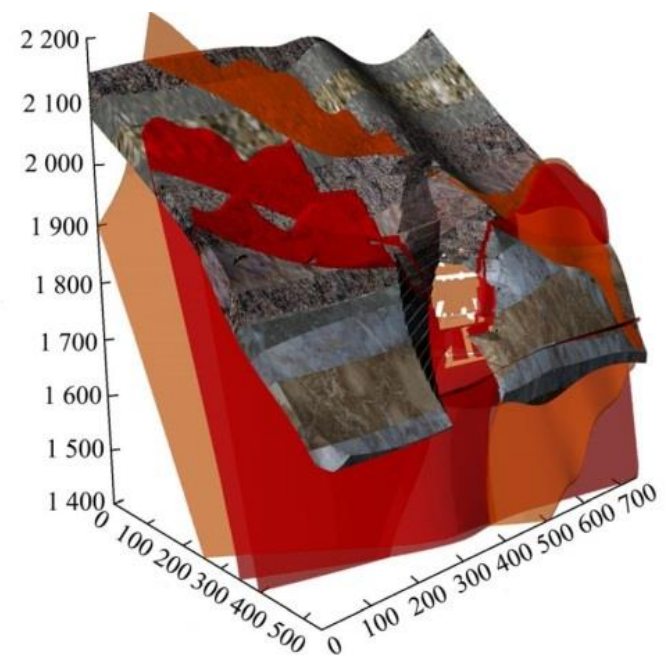

Figure 8. 3D Visualization Query of Geological Structure of Slope

\section{Conclusions}

Highway slope protection is a systematic project, it is not only a space concept, but also a time concept. From the space, any section of the slope are individuals, will be affected by the surrounding environment and geological conditions, slope protection design to to conduct a comprehensive assessment of slope topography, hydrological conditions, characteristics of the slope and surrounding environment, on slope stability and the requirements of environmental protection to make scientific reasonable consider, and then make a comprehensive protective measures. Slope protection should adhere to biological protection, engineering protection supplemented by the principle of combining, the proposed relying on the engineering slope protection in the main program biological protection mainly to properly reduce the engineering protection section, achieve coordinated with the areas along the ecological role.

In this paper for complex rock slope engineering of 3D geological modeling and 3D data structure, is to cut the NURBS surface slope engineering three-dimensional structure interface, application half B-rep structure of trimmed NURBS surface spatial topological relations. The geological structure, ground and underground excavation are realized by constructing the 3D solid model of complex slope engineering. Studies for tectonic slope engineering 3D entity model of the natural surface, ground and underground artificial construction material and geological structure interface trimmed NURBS surface generation method, geometric space geometric information and topological relationship established on the basis of the data for complex slope engineering. Based on the idea of "interface introduction and body division", a method of 3D solid topological relationship of B-Rep structure in complex slope engineering is realized. Demonstrate the feasibility of the application of desktop virtual reality technology X3D specifications to achieve three-dimensional visualization of slope engineering safety monitoring. Given the flexible X3D scene interaction and support of NURBS geometric modeling, the realization of the query $3 \mathrm{D}$ visualization based on $\mathrm{X} 3 \mathrm{D}$ slope engineering geological 3D virtual reality scene real-time dynamic visualization and virtual reality of the objects in the scene.

\section{Acknowledgments}

This research is supported by Social Science Fund Project of Hebei province: "Study on the rural ecological landscape pattern of suburb in the Construction of Beautiful Village". (HB16YS046) 


\section{References}

[1] L. Huafeng, D. Gang and J. Shiyao, "X3D:a next generation standard for interactive 3D graphics on Web”, Journal of System Simulation, vol. 13, (2001), pp. 199-203.

[2] M. Yongdong and T. Bin, "Research of structuring VR dynamic scenes based on Java and MySQL", Journal of System Simulation, vol. 17, (2005), pp. 2287-2291.

[3] S. Houlding, "3D geoscience modeling:computer techniuqes of geological characterization", Berlin, Springer-Verlga, (1994)

[4] S. Raghothama and V. Shapiro, "Boundary representation deformation in parametric solid modeling", ACM Transactions on Graphics, vol. 17, (1998), pp. 259-286.

[5] C. Daiyong, Z. Xiaodi and L. Qingyuan, "Application of OpenGL in 3D geological model visualization", Coal Geology of China, vol. 12, (2000), pp. 20-23.

[6] W. Qiang and X. Hua, "Study on 3D geological modeling and visualization", Science in China, Series D:Earth Science, vol. 34, (2004), pp. 54-60.

[7] Z. Liangfeng and P. Xin, "Design and development of 3D geological modeling and visualization system”, Rock and Soil Mechanics, vol. 27, (2006), pp. 828-832.

[8] L. Mingchao Denghua and Y. Jianmin, "3D visualization construction of complex engineering rock mass structure and its application", Chinese Journal of Rock Mechanics and Engineering, vol. 24, (2005), pp. $575-580$. 
International Journal of Security and Its Applications

Vol. 10, No. 6 (2016) 